Background: Peripheral primitive neuroectodermal tumour (pPNET) is typical for childhood and adolescent age. This kind of tumour belongs to the tumour family of Ewing sarcoma. The primitive neuroectodermal tumour is mainly localized in the central nervous system; less frequently it may also occur peripherally. The incidence of generalized peripheral primitive neuroectodermal tumour in adults is rare according to the available literature and treatment modalities are limited. The therapy is derived from protocols which were developed for the treatment of children. Material and methods: Patients with peripheral primitive neuroectodermal tumours were retrospectively evaluated according to therapeutic response and overall survival.

Results: From January 2000 to December 2010 eleven patients were diagnosed with peripheral primitive neuroectodermal tumour in the Cancer Centre in Hradec Králové, where eight of them were also treated. The median of age at the time of diagnosis was 45 years. The median overall survival was 571 days. The most commonly used cytotoxic agents were ifosfamide, doxorubicin and etoposide.

Conclusions: The results of treatment in patients with peripheral primitive neuroectodermal tumour are not encouraging, despite a multimodal therapeutic approach involving chemotherapy, radiotherapy and surgical treatment. It is therefore necessary to centralize patients in cancer centres and to offer them preferably participation in clinical trials.

Key words: primitive peripheral neuroectodermal tumour, Ewing sarcoma, chemotherapy.

\section{Our experiences in the treatment of peripheral primitive neuroectodermal tumour in the years 2000-2010 in the Cancer Centre in Hradec Králové}

Jindřich Kopeckýn, Otakar Kopecký², Peter Priester ${ }^{1}$, Jiří Petera', Ladislav Slováček ${ }^{1}$

1Department of Oncology and Radiotherapy, University Hospital, Hradec Králové 2Department of Oncology, Regional Hospital Náchod

\section{Introduction}

Based on cytogenetic, clinical and immunohistochemical similarities, peripheral primitive neuroectodermal tumour (PPNET) belongs to the Ewing sarcoma family of tumours [1, 2]. This group also includes Ewing's sarcoma (ES), rhabdomyosarcoma and desmoplastic small round cell tumour. All these tumours are characterized by their typical occurrence in childhood and adolescent age $[3,4]$.

Histopathologically, Ewing sarcoma family of tumours has similar morphology, which is found only in the neural crest during the embryonic ontogenesis [5]. The morphology is characterized by small round cells with uniform nucleoli and minimal cytoplasm $[6,7]$. The tumour cells express the following molecules: CD99 [8], vimentin $[9,10]$, neuron-specific enolase, S-100 protein, Leu-7 [11]. Ewing's sarcoma is considered to be a tumour derived from more undifferentiated cells and PPNET rather from differentiated cells $[12,13]$.

The oncogenesis of pPNET has a genetic background. The most common chromosomal abnormalities in up to $85 \%$ cases are reciprocal translocations of the q-arm between chromosomes 11 and 22 [2, 14]; other aberrations can occur such as t(21,22), t(7, 22), t(16 22) [7, 15, 16].

Unlike previous reports, there is no difference in terms of prognosis between ES and PPNET [17-20]. The main prognostic sign is the presence of metastases at the time of diagnosis [18, 21-23].

Due to the less frequent occurrence of this disease in adulthood, there are used treatment protocols based on protocols used for treatment of Ewing's sarcoma/pNET in childhood.

\section{Material and methods}

PPNET diagnosis was evaluated retrospectively from January 2000 to December 2010. The diagnosis was based on tumour morphology and immunohistopathological examination - presence of CD99 antigen and a negative panel of signs which can be found in other similar tumours (e.g. cytokeratin, chromogranin, synaptophysin, actin, desmin, myogenin, CD20, CD3). In some cases the diagnosis was confirmed by genetic examination. There were diagnosed 11 patients ( 7 men and 4 women). All patients were consulted with the Cancer Centre in Hradec Králové, where eight patients were then also treated (see their characteristics in Table 1). The most common primary tumour site was the retroperitoneum (Table 2). 
Table 1. Characteristics of treated patients

\begin{tabular}{|cccc}
\hline Age of patients to diagnosis time & Primary dissemination of tumour & Progression or dissemination during treatment \\
& No & No & No \\
42 & No & No & No \\
35 & No & Yes & Yes \\
56 & No & No & Yes \\
49 & Yes & Yes & Yes
\end{tabular}

Table 2. Primary localization of tumour at diagnosis time

\begin{tabular}{|ll|}
\hline Retroperitoneum & 4 \\
\hline Kidney & 1 \\
\hline Adrenal gland & 1 \\
\hline Thorax wall & 1 \\
\hline Nose cavity & 1 \\
\hline Muscle & 1 \\
\hline Bone & 1 \\
\hline Unknown origin & 1 \\
\hline
\end{tabular}

\section{Results}

From January 2000 to December 2010, there were diagnosed 11 patients with histological verification of peripheral primitive neuroectodermal tumour. The age range at the time of diagnosis was 8-72 years. At the time of diagnosis 8 patients were without evidence of dissemination. Three patients were sent after consultation with our department for further treatment to another cancer centre (the patients were 8,12 and 45 years old). During the therapy new local recurrence or metastatic involvement was verified in two patients. In three patients the therapy is ongoing since 31.12.2010. Median survival to the date 31.12.2010 was 571 days (range between 174 and 1517 days). In two patients there was administered more than one cyto- static line therapy. Five patients had as the therapeutic modality radiotherapy (Table 3). An overview of used cytostatics is shown in Table 4.

\section{Discussion}

Peripheral primitive neuroectodermal tumour is a tumour typical for childhood and adolescent age [3, 4, 24]. Peripheral primitive neuroectodermal tumour belongs to rare tumours with unsatisfactory treatment outcomes [25].

The main prognostic factor in ES/ PPNET is the presence of metastases at the time of diagnosis [18, 21-23, 26]. Fiveyear survival of patients with metastatic PPNET is according to available literature $9 \%$ to $33 \%$ [18, 21, 23, 27, 28]. Patients with lung metastases tend to have a better prognosis compared with patients with metastases involving the axial skeleton or bone marrow $[23,27]$.

Other negative prognostic signs are the primary location of the tumour, especially in the pelvic and axial bones [18, 22, 26, 29, 30], tumour size over $100 \mathrm{ml}[18,19$, 31], chromosomal aberrations [32] and the failure of first-line chemotherapy or failure of response to induction chemotherapy [28, 30, 33, 34].

Parameters such as immunohistochemistry or extraosseous tumour localization have no great prognostic significance. Age as a negative prognostic sign is reported in some studies as significant $[18,19,26]$, while other studies show no link between age and long-term survival [35, 36].

Table 3. Characteristics of treatment modalities and overall survival

\begin{tabular}{|c|c|c|c|}
\hline $\begin{array}{l}\text { Age of patients } \\
\text { to diagnosis time }\end{array}$ & $\begin{array}{l}\text { Overall survival from } \\
\text { diagnosis time }\end{array}$ & $\begin{array}{c}\text { Number of cytostatic } \\
\text { regimes }\end{array}$ & Radiotherapy \\
\hline 72 & 275 ongoing treatment & 1 & Yes \\
\hline 42 & 830 ongoing treatment & 1 & Yes \\
\hline 35 & 174 ongoing treatment & 1 & No \\
\hline 56 & 1517 & 1 & Yes \\
\hline 49 & 1058 & 3 & No \\
\hline 26 & 1265 & 3 & Yes \\
\hline 53 & 313 & 1 & Yes \\
\hline 42 & 241 & 1 & No \\
\hline
\end{tabular}


Table 4. Overview of used cytostatics: VIDE - vincristine, iphosphamide, doxorubicin, etoposide; IVAD - iphosphamide, vincristine, actinomycin D, doxorubicin; VAC - vincristine, actinomycin D, cyclophosphamide; MAID - mesna, doxorubicin, iphosphamide, dacarbazine

\begin{tabular}{|lccc}
\hline Name of cytostatics & Total number of cycles & Number of treatment line & Used \\
\hline Cisplatin/etoposide & 7 & 1 and 2 & 2 \\
\hline VIDE & 12 & 1 & 3 \\
\hline IVAD-3 & 6 & 1 & 1 \\
\hline VAC & 6 & 2 & 1 \\
\hline Iphosphamide/etoposide & 3 & 3 & 1 \\
\hline Cisplatin/cyclophosphamide & 3 & 3 & 1 \\
\hline Irinotecan monotherapy & 3 & 1 & 1 \\
\hline Doxorubicin, etoposide, cisplatin & 6 & 1 & 5 \\
\hline MAID & 6 & & 1 \\
\hline Radiotherapy & & 1 & 1 \\
\hline
\end{tabular}

Because of uncharacteristic symptoms, PPNET is often diagnosed already in an advanced stage. The most common sites of pPNET are soft tissue, bone, chest wall, small pelvis and extremities. Primary extraosseous occurrence is not frequent; there are described cases of primary PPNET in visceral organs such as pancreas, vulva, uterus, or, as in our patients, in the kidney or adrenal gland [37-41].

According to tumour localization there are various symptoms such as bone pain, cough, chest pain, dyspnoea, back pain or neurological symptoms. Within the diagnostic process it is often necessary to use multiple investigative techniques from $X$-ray and ultrasound to $C T$ and MRI examination, which provide basic information on the extent of the disease.

Within the differential diagnosis the following diseases should be considered: osteosarcoma, primary lymphoma of bone, sarcoma, metastatic tumours of other primary tumours. To determine the definitive diagnosis of ES/PPNET and thus to establish the optimal treatment options, histological verification should be carried out. Often it is not easy to make the diagnosis based only on the pathological description. A very helpful method today to provide the right diagnosis is cytogenetic examination. In our Cancer Centre this diagnostic tool has become a standard method.

There are limited data about treatment of PPNET in adults, because of its rare occurrence. Treatment of PPNET itself is based on a multidisciplinary approach and is often derived from the protocols used for the treatment of neuroectodermal tumours in childhood. Cooperation among the clinical oncologist, surgeon, radiotherapist, pathologist and radiologist is a prerequisite for the proper therapeutic strategy. The optimal therapeutic procedure, which is also preferred nowadays in our Cancer Centre, is neoadjuvant chemotherapy followed by radical surgery and adjuvant chemotherapy in combination with or without radiotherapy.

The cancer treatment of PPNET involves a combination of cytostatic agents given for long time even in seemingly nonmetastatic disease due to high risk of early haematological metastasis. Preferred cytostatics have changed over time. The basic cytotoxic agents used in our Cancer Centre include vincristine, doxorubicin, actinomycin D, cyclophosphamide, iphosphamide and etoposide. Peripheral PNET is a highly chemosensitive disease and nowadays the most frequently used therapy in our centre is based on the EuroEWING99 protocol. This protocol consists of 6 cycles of chemotherapy composed of vincristine, iphosphamide, doxorubicin and etoposide (VIDE) and one cycle of vincristine, actinomycin D and iphosphamide (VAI). For metastatic disease, high-dose chemotherapy is indicated with autologous transplantation [42].

The introduction of a multimodal approach into the treatment combining intensive chemotherapy with local treatment has improved the prognosis for patients with locally advanced disease [53]. However, this approach does not improve the prognosis in patients with metastases [44].

High-dose chemotherapy with autologous transplantation has been implemented for patients in the complete therapy response after induction chemotherapy since the 1980s. Some works have shown therapeutic benefit [45], but others have not [46]. The most commonly used cytotoxic agents in the myeloablative schemes are melphalan, etoposide, carboplatin, busulfan and cyclophosphamide [46].

In our centre we very often use radiotherapy for patients with PPNET. According to the most widely used protocol, EuroEwing 99, there are two modes: 1. Hyperfraction accelerated regime with two factions of 1.6 Gy per day with a total dose of $44.8 \mathrm{~Gy}$, stopping for 7-10 days after half of the total dose, with the possible irradiation of residual disease to a total dose of 54.4 Gy; 2. Conventional regime after chemotherapy with a total radiation dose of $45 \mathrm{~Gy}$ with fractionation of 1.8 Gy per day [42].

\section{Conclusions}

The introduction of new therapeutic approaches in chemotherapy, radiotherapy or surgery has led to improvement of the treatment outcomes in patients with localized PPNET. However, the situation is different 
in patients with generalized disease, where the response is inadequate. For this reason, it is appropriate to offer to these patients participation in clinical trials. The therapy should be centralized in cancer centres because of the rare occurrence of PPNET in adulthood.

\section{References}

1. Ambros IM, Ambros PF, Strehl S, Kovar H, Gadner H, Salzer-Kunt schik M. MIC-2 is a specific marker for Ewing's sarcoma and peri pheral primitive neuroectodermal tumors from MIC2 expression and specific chromosome aberration. Cancer 1991; 67: 1886-93.

2. Delattre O, Zucman J, Melot T, et al. The Ewing family of tumors. A subgroup of small round cell tumors defined by specific chimeric transcripts. N Engl J Med 1994; 331: 294-9.

3. Glass AG, Fraumeni JF. Epidemiology of bone cancer in children. J Natl Cancer Inst 1970; 44: 187-99.

4. Miller RW. Contrasting epidemiology of childhood osteosarcoma, Ewing's tumor, and rhabdomyosarcoma. Natl Cancer Inst Monogr 1981; 56: 9-15.

5. Horowitz ME, Malawer MM, Delaney TF, et al. Ewing's sarcoma family of tumors: Ewing's sarcoma of bone and soft tissue and the peripheral primitive neuroectodermal tumors. In: Principles and practice of pediatric oncology. Pizzo PA, Poplack DG (eds.). J.B. Lippincott, Philadelphia 1993; 795-821.

6. Scurr M, Judson I. How to treat the Ewing's family of sarcomas in adult patients. Oncologist 2006; 11: 65-72.

7. Stejskalová E, Jarosová M, Malis J, et al. Clinical relevance of chromosomal aberrations in bone and soft tissue tumors in children and young adults. Klin Onkol 2009; 22: 58-66.

8. Bernstein M, Kovar H, Paulussen M, Randall RL, Schuck A, Teot LA, Juergens $H$. Ewing's sarcoma family of tumors: current management. Oncologist 2006; 11: 503-19.

9. Navarro S, Cavazzana AO, Llombart-Bosch A, Triche TJ. Comparison of Ewing's sarcoma of bone and peripheral neuroepithelioma. An immu nocytochemical and ultrastructural analysis of two primitive neuroectodermal neoplasms. Arch Pathol Lab Med 1994; 118: 608-15.

10. Dierick AM, Roels H, Langlois M. The immunophenotype of Ewing's sarcoma. An immunohistochemical analysis. Pathol Res Pract 1993; 189: 26-32

11. Shanfeld RL, Edelman J,Willis JE, Tuason L, Goldblum JR. Immunohistochemical analysis of neural markers in peripheral primitive neuroectodermal tumor (pPNET) without light microscopic evidence of neural differentiation. Appl Immunohistochem 1997; 5: 78-86.

12. Koutecký J. Nádorová onemocnění děti a mladistvých. Univerzita Karlova, Praha 1997.

13. Horowitz ME, Tsokos MG, De Laney TF. Ewing's Sarcoma. CA Cancer J Clin 1992; 42: 300-20.

14. Aurias A, Rimbaut C, Buffe D, Dubousset J, Mazabraud A. Translocation of chromosome 22 in Ewing's sarcoma. C R Seances Acad Sci III 1983; 296: 1105-7.

15. Zhao L, Hayes K, Van Fleet T, Glassman A. Detection of a novel reciprocal t(16;22)(q11.2;q12) in a Ewing sarcoma. Cancer Genet Cytogenet 2003; 140: 55-7.

16. Prochazka P, Vícha A, Kodet R, et al. Ewing sarcoma family of tumors - molecular biology and genetics. Klin Onkol 2007; 20: 205-8.

17. Terrier P, Henry AM, Triche TJ, et al. Is neuroectodermal differen tiation of Ewing's sarcoma of bone associated with an unfavorable prognosis? Eur J Cancer 1995; 31: 307-14.

18. Cotterill SJ, Ahrens S, Paulussen M, Jürgens HF, Voūte PA, Gadner H, Craft AW. Prognostic factors in Ewing's tumor of bone: Analysis of 975 patients from the European Intergroup Cooperative Ewing's Sarcoma Study Group. J Clin Oncol 2000; 18: 3108-14.

19. Bacci G, Ferrari S, Bertoni F, et al. Prognostic factors in nonmeta static Ewing's sarcoma of bone treated with adjuvant chemotherapy: analysis of 359 patients at the Instituto Ortopedico Rizzoli. J Clin Oncol 2000; 18: 4-11.

20. Hartman KR, Triche TJ, Kinsella TJ, Miser JS. Prognostic value of histopathology in Ewing's sarcoma Long-term follow-up of distal extremity primary tumors. Cancer 1991; 67: 163-71.
21. Fizazi K, Dohollou N, Blay JY, et al. Ewing's family of tumors in adults: Multivariate analysis of survival and long-term results of multimodality therapy in 182 patients. J Clin Oncol 1998; 16: 3736-43.

22. Elomaa I, Blomqvist CP, Saeter G, Akerman M, Stenwig E, Wiebe T, Björk O, Alvegård TA. Five-year results in Ewing's sarcoma: The Scandinavian Sarcoma Group experience with the SSG IX protocol. Eur J Cancer 2000; 36: 875-80

23. Paulussen M, Ahrens S, Craft AW, et al. Ewing's tumors with primary lung metastases: survival analysis of 114 (European Intergroup) Cooperative Ewing's Sarcoma Studies patients. J Clin Oncol 1998; 16: 3044-52

24. Šmelhaus V, Koutecky J. Pacient summary of the clinic of paediatric oncology in teaching hospital in Motol and the development of the results of thein therapy in the years 1976-2000. Klin Onkol 2003; 16 (Suppl 2003): 85-92.

25. Baldini EH, Demetri GD, Fletcher CD, Foran J, Marcus KC, Singer S. Adults with Ewing's sarcoma/primitive neuroectodermal tumor: adverse effect of older age and primary extraosseous disease on outcome. Ann Surg 1999; 230: 79-86.

26. Sluga $M$, Windhanger R, Lang S, et al. A long-term review of the treatment of patients with Ewing's sarcoma in one institution. Eur J Surg Oncol 2001; 27: 569-73

27. Jenkin RD, Al-Fawaz I, Al-Shabanah MO, Allam A, Ayas M, Memon M, Rifai S, Schultz HP. Metastatic Ewing sarcoma/PNET of bone at diagnosis: Prognostic factors-a report for Saudi Arabia. Med Pediatr Oncol 2001; 37: 383-9.

28. Paulussen M, Ahrens S, Burdach S, et al. Primary metastatic (stage IV) Ewing tumor: survival analysis of 171 patients from the EICESS studies. European Intergroup Cooperative Ewing Sarcoma Studies. Ann Oncol 1998; 9: 275-81

29. Craft AW, Cotterill SJ, Bullimore JA, Pearson D. Long-term results from the first UKCCSG Ewing's Tumour Study (ET-1). United Kingdom Children's Cancer Study Group (UKCCSG) and the Medical Research Council Bone Sarcoma Working Party. Eur J Cancer 1997; 33: 1061-9

30. Kolb EA, Kushner BH, Gorlick R, et al. Long-term event-free survival after intensive chemotherapy for Ewing's family of tumors in children and young adults. J Clin Oncol 2003; 21: 3423-30.

31. Oberlin O, Le Deley MC, Nguyen Bui B, et al. Prognostic factors in localized Ewing's tumors and peripheral neuroectodermal tumors: The third study of the French Society of Paediatric Oncology (EW88 study). Br J Cancer 2001; 85: 1646-54.

32. Maurici D, Perez-Atayde A, Grier HE, Baldini N, Serra M, Fletcher JA Frequency and implications of chromosome 8 and 12 gains in Ewing sarcoma. Cancer Genet Cytogenet 1998; 100: 106-10.

33. Oberlin O, Patte C, Demeocq, et al. The response to initial chemotherapy as a prognostic factor in localized Ewing's Sarcoma. Eur J Cancer Clin Oncol 1985; 21: 463-7.

34. Bacci G, Ferrari S, Bertoni F, et al. Neoadjuvant chemotherapy for peripheral malignant neuroectodermal tumor of bone: recent experience at the Istituto Rizzoli. J Clin Oncol 2000; 18: 885-92.

35. Ferrari S, Bertoni F, Mercuri M, Sottili S, Versari M, Bacci G. Ewing's sarcoma of bone: relation between clinical characteristic and staging. Oncol Rep 2001; 8: 553-6.

36. Rosito P, Mancini AF, Rondelli R, et al. Italian cooperative study for the treatment of children and young adults with localized Ewing sarcoma of bone: a preliminary report of 6 years of experience. Cancer 1999; 86: 421-28.

37. Mentzel T, Bultitude MI, Fletcher CD. Primärer primitiver neuroektodermaler Tumor der Niere bei einem Erwachsenen. Pathologe 1994; 15: 124-8.

38. Mor Y, Nass D, Raviv G, Neumann Y, Nativ O, Goldwasser B. Malignant peripheral neuroectodermal tumor (PNET) of the kidney. Med Pediatr Oncol 1994; 23: 437-40.

39. Scherr GR, d’Ablaing G, Ouzounian JG. Peripheral primitive neuroectodermal tumor of the vulva. Gynecol Oncol 1994; 54: 254-8.

40. Danner DB, Hruban RH, Pitt HA, Hayashi R, Griffin CA, Perlman EJ. Primitive neuroectodermal tumor arising in the pancreas. Mod Pathol 1994; 7: 200-4.

41. Ren YL, Tang XY, Li T Ewing sarcoma-primitive neuroectodermal tumor of the uterus: a clinicopathologic, immunohistochemical and ultrastructural study of one case. Arch Gynecol Obstet 2011; 283: 1139-43. 
42. Ladenstein R, Pötschger U, Le Deley MC, et al. Primary disseminated multifocal Ewing sarcoma: results of the Euro-EWING 99 trial. J Clin Oncol 2010; 28: 3284-91.

43. Krasin MJ, Rodriguez-Galindo C, Davidoff AM, Billups CA, Fuller CE, Neel MD, Kun LE, Merchant TE. Efficacy of combined surgery and Irradiation for localized Ewings sarcoma family of tumors. Pediatr Bloood Cancer 2004; 43: 229-36.

44. Bertuzzi A, Castagna L, Nozza A, et al. High-dose chemotherapy in poor-prognosis adult small round-cell tumors: clinical and molecular results from a prospective study. J Clin Oncol 2002; 20: 2181-8.

45. Landenstein R, Lasset C, Pinkerton R, et al. Impact of megatherapy in children with high risk Ewing's tumors in complete remission: a report from the EBMT Solid Tumour Registry Bone Marrow Transplant 1995; 15: 697-705.

46. Kushner BH, Meyers PA. How effective is dose intensive, myeloablative therapy against Ewing's sarcoma/primitive neuroectodermal tumor metastatic to bone or bone marrow? The Memorial Sloan-Kettering experience and a literature review. J Clin Oncol 2001; 19: 870-80.

\section{Address for correspondence}

\section{Jindřich Kopecký}

Zakład Opieki Zdrowotnej MSWiA

Department of Oncology and Radiotherapy

University Hospital

Hradec Králowé, Czech Republic

Sokolska 581

e-mail: kopecjin@fnhk.cz 